\title{
El aspecto y sus cualidades tradicionales perfecto e imperfecto: análisis e inconsistencia*
}

JORGE ALBERTO VÁSQUEZ GONZÁLEZ**

Universidad de Antioquia, Colombia javg1980@hotmail.com

Recepción: 19 de septiembre de 2016 Aprobación: 04 de noviembre de 2016

Forma de citar este artículo: Vásquez González, J.A. (2017). El aspecto y sus cualidades tradicionales perfecto e imperfecto: análisis e inconsistencia. Cuadernos de Lingüística Hispánica, (29), 127-161. doi: http://dx.doi.org/10.19053/0121053X.n29.2017.5853

* Artículo de reflexión.

** Filólogo hispanista, Universidad de Antioquia, Colombia. Código ORCID: orcid.org/0000-0001-9976-7348 


\section{Resumen}

Se analizan el aspecto y sus cualidades tradicionales - perfecto e imperfecto- en ciertas formas verbales del español con el fin de mostrar un problema de inconsistencia conceptual. La distinción aspectual entre los tiempos simple y compuesto de la conjugación verbal española con arreglo a la terminología latina de infectum y perfectum, según se observa en la normatividad de la Real Academia Española (RAE), presenta un equívoco. Se propone, luego de una adecuada comprensión del concepto de participio, que forma el tiempo compuesto con el auxiliar haber, una terminología diferente para solucionarlo: continuo y discontinuo como las nuevas cualidades del aspecto. Lo que de paso conduce a plantear un nuevo accidente verbal: el estado. La metodología empleada en la presente investigación fue explicativa para precisar el término aspecto en el ámbito restringido de la lengua española; también, en menor grado, descriptiva, por cuanto se muestran ejemplos particulares y aclarativos que pueden confirmar la conveniencia de mantener el aspecto.

Palabras clave: participio, tiempo, aspecto, perfecto, imperfecto, estado.

\section{Aspect-perfect and imperfect traditional qualities. Analysis and inconsistency}

\section{Abstract}

Here, the Spanish grammatical aspect and its traditional qualities in perfect and imperfect verb forms are analyzed in order to expose a problem of conceptual inconsistency. Taking into account the Real Academia Española (RAE) normativity, there is a misperception in the aspectual distinction between the simple and compound tenses in Spanish, or in Latin, infectum and perfectum. After a proper understanding of the concept of participle, formed by the auxiliary to have, a different terminology is proposed to solve the problem: the terms continuous and discontinuous are proposed as new qualities of the grammatical aspect. Such a change would also suggest a new verbal accident: that of state. An explanatory methodology was implemented in this project, in order to specify the concept of aspect in the field of the Spanish language. To a lesser degree, a descriptive methodology was also used, by means of the presentation of specific, insightful examples to support the current concept of aspect.

Key words: Participle, Tense, Grammatical Aspect, Perfect, Imperfect, State. 


\section{L'aspect et ses qualités traditionnelles parfait et imparfait: analyse et inconsistance}

\section{Résumé}

On analyse l'aspect et ses qualités traditionnelles -parfait et imparfait- dans certaines formes verbales de l'espagnol afin de montrer le problème de l'inconsistance conceptuelle. La distinction aspectuelle entre les temps simple et composé de la conjugaison verbale espagnole conformément à la terminologie latine d'infectum et perfectum, selon on observe dans la normative de l'Académie Royale Espagnole (RAE), présente équivoque. On propose, après une bonne compréhension du concept de participe, qui forme le temps composé avec l'auxiliaire avoir, une terminologie différente pour le résoudre : continuum et discontinuum comme les nouvelles qualités de l'aspect. Ce qui s'est passé, nous conduit à aborder un nouvel accident verbal : l'état. On a utilisé une méthodologie explicative pour préciser le terme aspect dans la portée limitée de la langue espagnole; dans un degré moins important, celle-là est aussi descriptive, car on montre des exemples particuliers et explicatifs qui peuvent confirmer la convenance de maintenir l'aspect.

Mots clés: participe, temps, aspect, parfait, imparfait, état.

\section{0 aspecto e suas qualidades tradicionais perfeito e imperfeito: análise e inconsistência}

\section{Resumo}

Analisam-se 0 aspecto e suas qualidades tradicionais -perfeito e imperfeito- em certas formas verbais do espanhol com o fim de mostrar um problema de inconsistência conceptual. A distinção aspectual entre os tempos simples e composto da conjugação verbal espanhola com arranjo à terminologia latina de infectum e perfectum, segundo observa-se na normatividade da Real Academia Espanhola (RAE), apresenta um equívoco. Propõe-se, após uma adequada compreensão do conceito de particípio, que forma o tempo composto com o auxiliar haver, uma terminologia diferente para solucioná-lo: contínuo e descontínuo como as novas qualidades do aspecto. 0 que consequentemente conduz a propor um novo acidente verbal: o estado. A metodologia empregada na presente pesquisa foi explicativa para precisar o termo aspecto no âmbito restringido da língua espanhola; também, em menor grau, descritiva, por quanto se mostram exemplos particulares e de aclaração que podem confirmar a conveniência de manter 0 aspecto.

Palavras chave: particípio, tempo, aspecto, perfeito, imperfeito, estado. 


\section{Introducción}

En la gramática española, el término aspecto comporta tres nociones: 1) el aspecto léxico o semántico (modo de acción: Aktionsart); 2) el aspecto perifrástico o sintáctico; 3) el aspecto gramatical o morfémico, que es lo mismo que el verbal o flexivo (RAE, 2010, p. 430). En este artículo se analiza exclusivamente, desde una perspectiva teórica, el aspecto morfémico, uno de los seis accidentes verbales reconocibles en la lengua española, además de la voz, el modo, el tiempo, la persona y el número. Las dos primeras nociones del aspecto no serán tratadas aquí. Cuando se lea simplemente aspecto, se entenderá que se habla del gramatical.

Algunos autores niegan la condición de accidente verbal al aspecto. En ninguno de los 78 capítulos del magno libro coeditado por Ignacio Bosque \& Violeta Demonte (1999) «se dedica al aspecto verbal» (Moreno de Alba, 2003, p. 74), por inconveniente o innecesario. Rojo (1974) escribe: «Las formas verbales españolas no tienen función aspectual, sino una simple significación secundaria y ocasional que no afecta a lo morfológico. El aspecto no es un hecho del sistema» (p. 143). En otro lugar concluye: «Lo mismo que en el caso de las llamadas formas compuestas, no es necesario defender la existencia del aspecto como categoría funcional en el núcleo del verbo español para justificar el valor normalmente perfectivo de llegué o el valor normalmente imperfectivo de llegaba» (1990, p. 39). Su teoría de la temporalidad lingüística es suficiente, al parecer, para explicar las relaciones temporales entre las formas verbales, pero otro autor ha hecho notar que, en el fondo, no ha conseguido suprimir el aspecto (Vásquez González, 2015). ${ }^{3}$

¿Es conveniente o no sostener el aspecto como un accidente? Recurriremos a Emilio Alarcos Llorach (1970/1984), para quien, sin embargo, las formas verbales sí tienen función aspectual: no solo distingue entre llegaba y llegué, sino entre había llegado y

3 En un libro escrito con Manuel Mosteiro Louzao, anota Alexandre Veiga: «Ha sido especialmente defendida la funcionalidad del aspecto en el sistema verbal español buscando explicar la diferencia entre los contenidos gramaticales expresados por las formas canté y cantaba. Autores como Gili Gaya (1943), Alarcos Llorach (1949, 1975, 1994), Bull (1960), Ruipérez (1962), Černý (1969), Sławomirsky (1983), Hernández Alonso (1984b), Havu (1997), García Fernández (1999b) o Wilk-Racięzca (2000) se han pronunciado en este sentido» (2006, p. 17, n. 6). El mismo Veiga -de acuerdo con la posición de Eugenio Coseriu y de Guillermo Rojo, para quienes el aspecto es una categoría redundante, no funcional- presenta un texto con comentarios críticos sobre estas teorías (2004a, § 13.3 ss.) y recomienda el de Luis García Fernández \& Bruno Camus Bergareche (2004) para las diferentes interpretaciones de este problema concreto. Textos pertinentes son también los de Rojo (1990, pp. 17-41) y Veiga (1992, 2004b, 2008). 
bube llegado, como se verá en $\S 1$ 1.4. En mi opinión, la funcionalidad del aspecto para el español actual no es solo defendible entre las formas simples llegaba y llegué, sino también entre las compuestas había llegado y hube llegado.

La Real Academia Española (RAE) admite el aspecto como un accidente. De hecho, en la nomenclatura de la conjugación verbal utiliza todavía las denominaciones pretérito perfecto o pretérito pluscuamperfecto. Lo que se ha de observar es el arraigo del término perfecto, proveniente de la gramática latina, para designar una acción terminada. Se suscribe a continuación la nomenclatura vigente de la $\operatorname{RAE}(2010$, p. 428) para reconocer cuáles son las formas personales objeto de estudio (en el modo indicativo, la primera conjugación, la primera persona y el número singular):

Tabla 1. Algunos tiempos simples y compuestos de la conjugación verbal de la RAE

\begin{tabular}{|c|c|}
\hline Tiempos simples & Tiempos compuestos \\
\hline Presente & Pretérito perfecto compuesto \\
amo & be amado \\
\hline Pretérito perfecto simple & Pretérito anterior \\
amé & bube amado \\
\hline Pretérito imperfecto & Pretérito pluscuamperfecto \\
amaba & babia amado \\
\hline
\end{tabular}

Por razones de espacio, se omiten las formas verbales de los modos subjuntivo e imperativo y las de futuro (amaré, habré amado, amaría, habría amado). Las de subjuntivo también adoptan el aspecto. Por ejemplo, la forma haya amado se denomina pretérito perfecto. Para nuestro propósito, pueden bastar las formas suscritas del modo indicativo. No está de más restringir y recordar que serán consideradas en su valor temporal primario, aparte de los usos no rectos.

En la primera sección, sobre el aspecto del tiempo compuesto español, se muestra un equívoco al distinguir entre las formas había amado y bube amado. Si se afirma como la RAE y muchos autores- que ambas son de aspecto perfecto debido al mismo participio amado, no se distinguirán entonces en el aspecto. En realidad, el participio no es el definidor del aspecto, sino el auxiliar haber. Es importante insistir en que el participio no expresa el aspecto -tampoco la persona ni el tiempo-, sino la acción (verbal) como perfecta, esto es, totalmente hecha o terminada en algún tiempo: había amado (pasado), he amado (presente), habré amado (futuro). El problema fundamental (teórico) del artículo es el siguiente: las cualidades tradicionales perfecto e imperfecto, legadas del latín, no son en el español del todo adecuadas para el aspecto, por cuanto presentan el equívoco. 
El remedio, que es la justificación principal de este escrito, es proponer otras cualidades: continuo y discontinuo. Son útiles no solo para distinguir entre amaba y amé, como se ha venido haciendo casi de manera privativa para sostener el aspecto como un accidente verbal, sino también entre babía amado y hube amado. ${ }^{4}$

En la segunda sección, a fin de validar que tienen función aspectual, se compara las formas de la tabla 1, aplicando las mismas cualidades: continuo y discontinuo. Lo que conduce a plantear en la conclusión un nuevo accidente verbal, presuntamente no entrevisto por los lingüistas y sobre el que, por supuesto, no existe una bibliografía especializada contemporánea: lo denomino, sensu stricto, el estado. Que el lector nos conceda este planteamiento de algo incipiente, el preliminar de un tema que requiere una profundización en otro artículo. Es el corolario del examen terminológico y conceptual de las cualidades tradicionales del aspecto para hacer notar el problema expuesto: el equívoco.

Por lo demás, no nos fijaremos en la historiografía sobre las formas verbales o en la razón de las denominaciones para ellas -como se ven en la tabla 1-.

\section{El aspecto del tiempo compuesto}

\subsection{El auxiliar baber: definidor del aspecto}

Según el Diccionario de Rufino José Cuervo (1993), «las formas de haber se unen al participio del verbo que se conjuga para formar los tiempos compuestos de la voz activa. En función de auxiliar la gramaticalización es completa. Su aportación no es léxica sino morfológica, indica la voz, el número, el tiempo y el modo de la expresión verbal» (p. 10). ¿También la persona y el aspecto? Para Escarpanter (1994), el auxiliar haber es un verdadero morfema: mientras que en las formas simples la desinencia indica los accidentes gramaticales del verbo, en las compuestas, «haber, con sus propias desinencias, es el que nos da los accidentes del verbo que se conjuga. El participio pasivo solo informa del significado [léxico] de la forma verbal» (p. 149). El haber no tiene «significado pleno [o lexical], sino sólo significado gramatical» (p. 165); expresa «tiempo, modo, aspecto, número, persona y voz» (p. 165), todos los seis accidentes verbales hoy comúnmente reconocibles. Algo similar refiere José García Martín (2001, p. 12).

4 No es aquí el lugar para una crítica detenida de las categorías de Comrie (1976, p. 25) sobre lo imperfecto, a saber: habitual y continuo, progresivo y no progresivo; tampoco para un examen del rechazo a la distinción entre progresividad y no progresividad (Bybee, Perkins \& Pagliuca, 1994), de la propuesta de Pier Marco Bertinetto (1986) o de quien divide el imperfecto en progresivo, continuo y habitual o el aspecto en perfectivo, imperfecto y perfecto (García Fernández, 1998). Nos basta establecer la oposición entre continuo y discontinuo, relativa al aspecto morfémico, la cual no tiene nada que ver con las diversas clasificaciones del aspecto léxico o con alguna tipología del imperfecto; se deriva de precisar la oposición tradicional entre perfecto e imperfecto. No sobra advertir que este artículo se ciñe a las formas objeto de estudio (cf. la tabla 1); no aborda el tema del estar, ir o seguir + gerundio. 


\subsection{El equívoco entre había amado y bube amado}

Por lo visto, el auxiliar haber, no el participio, define el aspecto del tiempo compuesto. ¿Cómo distinguir estos tiempos compuestos, había amado y hube amado? ¿Son igualmente aspectuales? Del primero se dice que es pretérito pluscuamperfecto, y del segundo, pretérito anterior. Sin duda, son igualmente temporales: se refieren al pretérito. $\mathrm{Si}$ se dice que son de aspecto perfecto, son, pues, igualmente aspectuales. Por lo que no hay nada que los distinga, lo que es discutible.

Si todos los tiempos compuestos de voz activa son de aspecto perfecto, ¿por qué razón denominar uno pluscuamperfecto, o sea, más que perfecto? ¿No es una exageración? Si es para distinguirlo del pretérito perfecto (he amado), la razón nominal no parece suficiente. En Elio Antonio de Nebrija (1492), el pretérito pluscuamperfecto es lo mismo que el «pasado más que acabado»: «es aquel [tiempo] en el cual alguna cosa se había hecho cuando algo se hizo, como yo te había amado, cuando tú me amaste» (III). En otras palabras, primero te amé, luego me amaste. Se dice pluscuamperfecto por una razón: la anterioridad de una acción pasada con respecto a otra también pasada. Con todo, en el pluscuamperfecto, la acción del verbo auxiliado es aún de aspecto perfecto. La razón no es aspectual, pues tanto había amado como amaste son igualmente de aspecto perfecto, sino de anterioridad.

\subsection{Perfecto e imperfecto: problema terminológico y conceptual}

Los tradicionales términos perfecto e imperfecto, como conceptos divisorios del aspecto, normalmente aplicados por la RAE a los tiempos simple y compuesto en los modos indicativo y subjuntivo, son problemáticos. Muchos gramáticos los han repetido. Por ejemplo, para Escarpanter (1994), lo perfecto «existe en todas las formas verbales en las que va implícito el término de la acción; son estas formas el pretérito indefinido de indicativo (jugué) y todas las formas compuestas tanto de indicativo como de subjuntivo» (p. 150), y lo imperfecto «existe en las formas en que el fin de la acción no está implícito; son los tiempos simples menos el pretérito indefinido de indicativo» (p. 150). Asimismo, para Blanco Hernández (2005), «todos los tiempos simples, menos el pretérito indefinido, indican el aspecto imperfectivo, y todos los tiempos compuestos y el pretérito indefinido, el aspecto perfectivo» (pp. 21-22). Igualmente para Gili Gaya (1943/1981): «Son imperfectos todos los tiempos simples de la conjugación española, con excepción del pretérito absoluto [...]. Son perfectos el pretérito absoluto [...] y todos los tiempos compuestos» (p. 149). Incluso para Rojo (1990, pp. 34-37), con algunas reservas. ${ }^{5}$

5 A fin de evitar confusión, se ha de prevenir que aquí no se usa, como en la terminología de Bernard Comrie (1976), la distinción 
Es cierto que unas formas verbales son perfectas y otras son imperfectas en el sentido normal y conservador de que las primeras expresan una acción terminada y las segundas la expresan no terminada, como de manera similar sostiene la RAE (2010, p. 430). Pero lo perfecto y lo imperfecto ya no deberían ser las cualidades del aspecto. Precisamente, el verbo auxiliar haber define el aspecto del tiempo compuesto. Tal aspecto es un accidente verbal consecutivo de cierto morfema. Así, conforme al criterio morfológico, en había amado, el tiempo de habia es pasado y el aspecto es imperfecto; en bube amado, el tiempo de bube es también pasado pero el aspecto es perfecto. Por lo que, paradójicamente, no todos los tiempos compuestos son de aspecto perfecto. ${ }^{6}$ Según el participio, la acción es siempre en todos ellos perfecta, es decir, se efectuó totalmente.

¿No puede haber acaso distinción aspectual entre había amado y bube amado?

\section{$1.4 \mathrm{El}$ aspecto entre babía amado y hube amado, según Alarcos}

Léase con esmero lo que escribe Alarcos (1970/1984):

Las oposiciones cantaba / canté, habia cantado / hube cantado reflejan una diferencia de aspecto. Cantaba no indica una diferencia temporal respecto a canté, sino sólo aspectual: es no terminativo, mientras canté es terminativo. En principio, entre babía cantado y bube cantado debería existir la misma diferencia; pero como son formas compuestas y, por tanto, miembros positivos de la correlación aspectual sintagmática, el problema se complica; había cantado expresa un proceso delimitado, con respecto a canté (no delimitado), pero un proceso no terminativo con respecto a bube cantado; por otro lado, bube cantado expresa un proceso delimitado, frente a canté (que, aunque no delimitado, ya indica su término), y un proceso terminativo frente a había cantado (que a su vez es un proceso delimitado). La forma bube cantado [...] indica dos veces el término: de ahí que pase a igualarse con canté (como en la lengua antigua) o que pase a igualarse con babía cantado (como en la lengua moderna, en la que esta última forma prevalece) (pp. 80-81).

A mi modo de ver, el problema se complica con la terminología que usa Alarcos (1970/1984), quien sigue a Jens Holt (1943): la distinción entre el «aspecto flexional» y el «aspecto sintagmático»:

entre perfecto -del inglés perfect, para eventos pasados y relevantes en el presente: «the perfect indicates the continuing present relevance of a past situation» (p. 52) - y perfectivo -del inglés perfective, para eventos terminados en el pretérito: «the only new semantic element introduced by the perfective is that of the termination of the situation» (p. 19)-, pese a que perfecto y perfectivo, en otros discursos, parezcan o puedan significar lo mismo. Se limita simplemente al uso del término perfecto, expresivo de la acción hecha y terminada y contrapuesto al imperfecto.

6 Es semejante en los tiempos simples de indicativo: el tiempo de amaba es pasado y el aspecto es imperfecto; el de amé es también pasado, pero el aspecto es perfecto. 
El aspecto flexional opone en español dos formas de cada verbo: imperfecto y perfecto simple, cantaba / canté, que indican, respectivamente, el proceso sin su término y el proceso con su término; esto es, el aspecto no-terminativo y el aspecto terminativo. El aspecto sintagmático opone en español todas las formas simples a las compuestas: canto / he cantado, etc., que indican, respectivamente, el proceso sin su término y el proceso con su término; esto es, el aspecto no-delimitativo y el aspecto delimitativo. El aspecto flexional se da sólo en el pasado; el sintagmático en todos los tiempos (pp. 78-79).

La misma distinción parece sutil. Para Alarcos, no hay entre una forma simple y la compuesta correlativa -como entre amo y be amado, amaba y babía amado, amé y bube amado, etc.- distinción temporal, sino aspectual: "entre las formas compuestas y las simples [...] lo que las distingue no es el "tiempo", aunque en el uso lingüístico se pueda observar que una forma simple y la compuesta correspondiente indican diversas épocas temporales. La diferencia fundamental entre unas formas y otras en el sistema de la conjugación, es una diferencia de "aspecto"» (p. 73).

Ante todo, ¿qué es el aspecto? Otra vez Alarcos: «Según Holt, el "aspecto” expresa el término o el no-término del proceso» (p. 78): «Un proceso "sin término" es una acción en movimiento hacia su terminación; un proceso "con su término" indica una acción que ha llegado a ese punto de terminación y se aleja de él» (p. 78). En otras palabras, el aspecto expresa el intermedio de una acción o su final. Curiosamente, nunca su principio. ${ }^{7}$ En los tiempos simples, el aspecto de amé muestra el final de la acción, y el de amo y amaba, su intermedio. ¿Qué decir de amaré? Por lo pronto, se omite la respuesta. En los tiempos compuestos, cuyo participio, como se vio, significa que la acción es perfecta, el aspecto muestra siempre su final, ipero del mismo modo?

Propiamente, todos los tiempos compuestos que aparecen en el modelo de la conjugación verbal tienen el mismo participio con el idéntico significado de la acción perfecta, pero difieren en cierto morfema del auxiliar, por lo que necesariamente difieren en el aspecto. No basta decir, conforme al criterio del «aspecto sintagmático»-de la «expresión de la anterioridad» (Alarcos, 1970/1984, p. 119) con respecto a la forma simple correlativa-, que todos son de aspecto delimitativo. El problema se complica, sí, con los

$7 \quad$ El intermedio, es decir, entre el principio y el final, después de comenzar y antes de terminar. No necesariamente la acción va por la mitad, sino en algún momento entre ambos extremos. Hay que considerar que ninguna forma verbal simple o compuesta en nuestro idioma explicita la duración de la acción, esto es, cuánto dura, ha durado o durará: «El tiempo no tiene en cuenta [...] lo que dura la acción: expresa el momento en que ésta se ha ejecutado (pretérito o pasado), se ejecuta (presente) o se ejecutará (futuro)» (Pérez-Rioja, 1952/1987, § 200). Valga anotarlo: en un ejemplo como comí ayer, se entiende que la acción finalizó: es perfecta; en comí ayer a las siete, se entiende lo mismo, aunque por el complemento circunstancial de tiempo se enfoque la acción en el principio. Pero el pretérito simple,por sí y gramaticalmente, se refiere siempre al final de la acción. 
tiempos compuestos había amado y hube amado: son igualmente de aspecto delimitativo. ¿Cómo distinguirlos? Desde luego, «debería existir la misma diferencia» que entre amaba y amé. De modo inconsecuente, introduce Alarcos, para poder distinguirlos, el criterio del «aspecto flexional», que es exclusivo de esos dos tiempos simples.

Después de todo, ¿qué significa delimitativo? Concluye Alarcos: «Las formas simples -y con ellas canté- no delimitan el proceso [de la acción], no señalan la "sucesión de las cosas" [la suite des choses, según Holt]; las formas compuestas lo delimitan y señalan la sucesión de las cosas» (p. 83). A primera vista, parece una explicación interesante, pero opaca y no decisiva para distinguir entre había amado y bube amado.

\subsection{Propuesta de otras cualidades del aspecto: continuo y discontinuo}

Hace falta una terminología más accesible. Comenta Viejo Fernández (1998): «En una revisión posterior sobre sus ideas (matizadas ahora expresamente por el influjo de Weinrich) Alarcos reserva el término aspecto solamente a la oposición imperfecto/perfecto y el de anterioridad al más general formas simples/formas compuestas [...]. Por su parte, Guillermo Rojo [...] niega el valor aspectual de unas y otras, limitando su definición de las mismas a criterios puramente temporales» (p. 26). El aspecto ha sido una categoría verbal muy controvertida por los lingüistas, tanto como el concepto de significado. Unos niegan su existencia, otros la afirman. La terminología es tan dispar que es mayor la confusión y menor el consenso (cf. al respecto Guzmán \& Herrador del Pino, 2002; Esteves, 2004 y Westerholm, 2010). Pese a la divergencia -no es aquí el lugar para la discusión y el contraste-, soy del parecer al menos de Alarcos: es defendible el aspecto como una categoría funcional, no redundante -e independiente del tiempo y del modo-. Para que no haya un equívoco -como se vio entre babía amado y bube amado, indistintos en cuanto al aspecto-, conviene no decir que la acción en todos los tiempos compuestos es de aspecto perfecto. Los términos perfecto e imperfecto sí son apropiados en la voz activa de la gramática latina, que solo tiene tiempos simples, pero no igualmente en la española, que añade tiempos compuestos. Pero son más apropiados en la gramática griega que en la latina, según Viejo Fernández (1998):

Podría decirse que el problema del aspecto en el ámbito de las lenguas románicas parece viciado desde los orígenes. Ya la gramática latina, desde Varrón (no así autores posteriores), al agrupar las formas verbales de aquella lengua en dos series aspectuales (infectum/perfectum), no hacía sino aplicar al latín conceptos más 
adecuados al sistema verbal griego, tal como había sido descrito por las gramáticas estoicas, que a la propia lengua de Roma (p. 24). ${ }^{8}$

Opino que ha valido la pena la herencia grecolatina. No puede ser una reliquia. La evidencia es que el aspecto es una categoría distinta del tiempo: lo perfecto y lo imperfecto expresan, respectivamente, el final de la acción o su intermedio, lo que no es insignificante. Luego del nacimiento de las formas compuestas romances -o de los circunloquios, como expresa Nebrija-, la cuestión es afinar el concepto para ellas, tan diferentes de las formas griega y latina. ${ }^{9}$

Serían preferibles, para los tiempos españoles simple y compuesto, los términos continuo y discontinuo como conceptos divisorios del aspecto. Por cierto, no dependen del significado léxico del verbo, cuyo aspecto puede ser «momentáneo» (disparar, despegar, clavar), «repetitivo» (martillar, remar, escribir), «duradero» (crecer, madurar, avanzar), «frecuentativo» (acostumbrar, soler, habituar), «perfectivo» (completar, terminar, finalizar), «reiterativo» (volver, insistir, repetir) o «ingresivo» (iniciar, empezar, comenzar) (Fuentes de la Corte, 2005, p. 368); dependen de cierto morfema. ${ }^{10}$ El aspecto continuo o discontinuo de una acción es «compatible» (lo tomo prestado de Alarcos, 1994/2000, § 225, p. 161) con su aspecto momentáneo, repetitivo, duradero, etc. En disparó con puntería una sola bala, el aspecto de la acción de disparar es discontinuo, según cierto morfema verbal -en este caso, -ó-, y momentáneo, según su significado léxico; en disparaba con puntería una sola bala, continuo - el morfema -ba- y momentáneo. ${ }^{11}$

Por lo argumentado, lo perfecto no es ya una cualidad del aspecto, sino que, propiamente, se refiere a la acción perfecta o terminada. Así, había amado y bube amado son igualmente de acción perfecta, según el participio, pero, según el auxiliar, son de aspecto continuo y discontinuo. Asimismo, amaba y amé son de aspecto continuo y discontinuo. El participio del tiempo compuesto, se insiste, significa que la acción es perfecta, pero no expresa el tiempo de ella o su aspecto. Solo el auxiliar haber los expresa.

8 Cf. también Tobón de Castro \& Rodríguez Rondón (1974) y Veyrat Rigat (1993, cap. 1).

9 Escribe Carrasco Gutiérrez (2008): «Una innovación de las lenguas romances con respecto al latín es la creación de formas perifrásticas verbales para la expresión de anterioridad» (p. 14), esto es, la forma típica haber + participio.

10 Para una amplia información sobre el aspecto léxico, cf. Elena de Miguel (1999, pp. 2977-3060), Margaret Lubbers Quesada \& Ricardo Maldonado (2005) y María Martínez Atienza (2014, pp. 279-302).

11 En Pablo bebe mucho, el aspecto de bebe es continuo -se percibe la acción en su intermedio-; y en cuanto al significado léxico del verbo, puede ser de aspecto frecuentativo. Pero el aspecto morfémico no se fija en el significado léxico ni se reduce a él. En Pablo ha bebido mucho, el aspecto de ha bebido es también continuo, por el auxiliar -se percibe la acción en su final, según la perfección gramatical-, pero no se nota ya el aspecto frecuentativo. 


\subsection{Precisión sobre el aspecto de la forma compuesta babía amado}

Una parte de la vieja terminología de Nebrija, proseguida por muchos gramáticos y la RAE, con frases como pretérito imperfecto o pretérito pluscuamperfecto, parece, por lo visto, algo imprecisa. Nebrija, que instituye el paradigma de la conjugación verbal española con arreglo a la terminología latina, difumina la distinción entre el tiempo simple y el compuesto. Amo, amabam y amavi (respectivamente, el presente, el pretérito imperfecto y el pretérito perfecto, tiempos simples latinos de voz activa y de modo indicativo) se conservaron en el español con una pequeña alteración formal: respectivamente, amo, amaba y amé. Del pretérito pluscuamperfecto amaveram, otro tiempo simple de voz activa y de modo indicativo latino, quedó la forma amara, alterada en el significado gramatical, que Nebrija traslada al pretérito imperfecto de voz activa y de modo subjuntivo español. El futuro imperfecto amabo y el futuro perfecto amavero, los restantes tiempos simples, se perdieron.

Por una razón acomoda Nebrija en el pretérito pluscuamperfecto de indicativo el tiempo compuesto había amado: el significado gramatical de la anterioridad. Pero el contenido de la forma compuesta había amado no se ajusta enteramente -no equivale con exactitud- a la forma simple amaveram, que desde el pretérito no siempre expresa el final de la acción (perfectum), sino el intermedio (infectum) (Penny, 2008, p. 192). Pluscuamperfecto significa que la acción es de aspecto perfecto y anterior a otra. ${ }^{12}$ Sin duda, en había amado la acción es perfecta, pero su aspecto, como se vio, es continuo. Nebrija hubiera podido analizar más la morfología de los tiempos compuestos y habría podido separar las formas verbales en simples y compuestas, sin respetar demasiado la terminología latina.

\subsection{Perfección gramatical y perfección real}

Antes de pasar a la segunda sección, es indispensable comprender la distinción entre la perfección gramatical y la perfección real de la acción. No deberían confundirse ambos conceptos. Aunque una acción, gramaticalmente, se conciba como perfecta, puede continuar durando en la realidad, según el sentido lexical y el contexto. Es habitual con las formas amé y he amado.

Gili Gaya (1943/1981, § 119) explicó bien la diferencia. Ha notado Andrés Bello (1931): «Amé no es siempre un puro pretérito, antes parece emplearse muchas veces

12 Refiere Alarcos (1994/2000), siguiendo a Bello: «Las formas compuestas [españolas] señalan respecto de las [simples] un contenido de anterioridad [temporal]» (§ 199). Lo que «justifica plenamente la terminología adoptada por Andrés Bello, que llamó ante-presente a has cantado, ante-futuro a habrás cantado, ante-pospretérito a babrías cantado, etc.» (§ 229). 
como verdadero ante-presente» ( $(181)$. Habiendo dado el ejemplo de una estrofa de Samaniego -«iAy de mí, miserable, / infeliz avecilla, / que antes volaba libre, / y ya lloro cautiva! / Perdí mi nido amado; / perdí en él mis delicias; / al fin perdílo todo, / pues que perdí la vida»-, explica que este uso es metafórico. Se puede decir be perdido, mas no sería igual ni poético. Agrega Bello: «Algunas veces [...], sin que haya metáfora alguna, se usa el pretérito por el ante-presente, sobre todo en poesía. Este uso es un arcaísmo en que la lengua castellana retiene el valor latino de amavi, que abrazaba los dos significados de amé y he amado» (§ 181). Con una cita de Calderón de la Barca - «Gocé felice, y desgraciado lloro: / ¿cuándo no fué inconstante la fortuna?»-, aclara: «Ha sido sería más propio que fué, aunque no tan poético».

Lo que aquí importa reconocer es que se puede usar correctamente la forma simple o la compuesta, pero no como si fueran gramaticalmente lo mismo. Acaso por este motivo -dicho sea de paso- existen algunas veces usos semejantes de las formas amé y he amado. Si nos basamos en la distinción de Comrie (1976) entre perfecto y perfectivo (cf. la nota 3), ocurre que be amado puede designar eventos perfectivos en algunos dialectos peninsulares (Schwenter \& Torres Cacoullos, 2009): el año anterior me he comprado una casa -frente a me compré-; por el contrario, amé puede designar eventos perfectos en algunos dialectos suramericanos (Ocampo, 2008).

La forma latina amavi (amé o he amado) es de tiempo pasado o de tiempo presente, dependiendo del caso, pero siempre de aspecto perfectivo, según Ralph Penny (2008, p. 192). Hay que advertir que Penny (2008) distingue entre imperfectivo - «el hablante no está preocupado por el principio o fin de la situación, sino tan sólo por su desarrollo en el tiempo» (p. 192)- y perfectivo. Aparte de esto, conviene señalar tres casos:

1. Perfección gramatical y real: no continúa la duración de la acción ni el efecto de la acción. El principio y el final de la acción pertenecen al pasado, próximo o remoto. Es la forma amavi de tiempo pasado. Corresponde estrictamente a la forma simple amé. Tiene un carácter puntual. Comenzó y terminó. Por ejemplo, llovió ayer; estuve en el colegio el lunes; jugué un rato. La perfección de la acción es a la vez gramatical y real. Sonaría forzado ba llovido ayer, si estuviésemos de acuerdo con la norma, de modo que aquí se usaría solo la forma simple.

2. Perfección gramatical y real: continúa el efecto de la acción. El principio y el final de la acción pertenecen al pasado, próximo o remoto, pero algún efecto de ella es relevante en el presente. Corresponde estrictamente a la forma compuesta be amado. Aunque la acción, expresada con la misma forma, se concibe como real y gramaticalmente perfecta, algún efecto de ella persiste en el presente. En el primer ejemplo de Bello -«perdí 
mi nido amado»-, se puede decir también, dentro de la norma, he perdido. Pero no es que el pretérito «parece emplearse muchas veces como verdadero ante-presente» 0 con el valor del perfect de Comrie (1976), sino que aquí es correcto usar las dos formas, advirtiendo de antemano que no expresan lo mismo por ser gramaticalmente distintas. El auxiliar en be perdido es el que explicita el aspecto continuo. En perdí, el aspecto es discontinuo.

3. Perfección gramatical, no real: continúa la duración de la acción. El principio de la acción pertenece al pasado, próximo o remoto, pero no el final de ella, que aún dura 0 , por lo menos, puede durar en el presente. Es la forma amavi de tiempo presente. Corresponde al pretérito o al antepresente -utilizando la terminología de Bello- ${ }^{13}$ La acción se concibe como gramaticalmente perfecta, cuando no es, según el contexto, realmente perfecta. Sobre el segundo ejemplo que aporta Bello - «icuándo no fué inconstante la fortuna?»-, se puede asimismo decir, dentro de la norma, ba sido, pero la acción de ser inconstante continúa en el presente. Por cierto, Bello (1931, § 181) aduce que fue es incluso sustituible por es. Resulta que hay tres expresiones gramaticales diferentes (fue , ba sido y es) para la misma realidad de la fortuna inconstante.

Por lo demás, se ha discutido que he amado puede tener, frente a amé, aspecto "imperfecto". Lo recuerda Veiga (2011, p. 441), comentan Moreno de Alba (2003) y García Fajardo (2011) y amplifica Colombo Airoldi (2004) (Vásquez González, 2015, p. 209, n. 17). La distinción entre la perfección gramatical y la perfección real es útil aquí. Gramaticalmente, he amado es perfecto: el participio expresa la acción terminada. Lo imperfecto, debido al auxiliar be:

Se relaciona más bien con querer relevar la continuidad (en el presente) de algún efecto de [la acción], aunque siga durando realmente. Si ya no dura más, la perfección será entonces real: en un momento del pasado, próximo o remoto, terminó la acción. No es necesario que el término de ella sea "reciente"; puede ser "antiguo" según el contexto: es el único cuadro que he pintado en mi vida, en que la acción de pintar se concibe como gramatical y realmente perfecta en un momento del pasado -pongamos el año 1950-, pero que es relevante, por decirlo así, algún efecto de ella con relación al ahora (Vásquez González, 2015, p. 209, n. 17).

Pareciéndose a la forma latina amavi de tiempo presente, amé y he amado pueden tener algo en común: no siempre expresan la perfección real de la acción, sino solo la perfección gramatical, según vimos en el tercer caso. Con ambas formas la acción se

13 A veces el pretérito es indefinido, indicador de una acción ininterrumpida (cf. la nota 24). Vásquez González (2015, p. 209) considera la forma bube amado como capaz de expresar lo indefinido. Es dudoso encontrar un ejemplo. La forma había amado es más capaz de expresarlo, por su analogía con he amado, como veremos en $\S 2.1$ y $\S 2.4$. 
concibe como gramaticalmente perfecta, aunque siga durando realmente -desde luego, esto no es concorde con la terminología de Penny, para quien be amado cae en el "aspecto perfectivo"-.

Alguien puede decir: vaya, comí mucho $-\mathrm{y}$ todavía sigue comiendo- o vaya, be comido mucho -y todavía sigue comiendo-. Ya que por el contexto no expresan la perfección real de la acción, ambas formas son admisibles; en cuanto a la perfección gramatical, son desiguales (en el aspecto y el tiempo) debido a su morfología, si bien son correctamente sustituibles. Como veremos mejor en $\S 2.7$, el tiempo de be comido es presente y su aspecto es continuo; el tiempo de comí es pasado y su aspecto es discontinuo.

Este ejemplo de Alarcos (1994/2000), toda la vida la quiso con locura (p. 161), tiene un «sentido de persistencia» por la frase toda la vida. Aunque el aspecto de quiso es discontinuo, el pretérito puede ser indefinido, conforme al tercer caso (perfección gramatical, no real), de manera que, realmente, todavía la quiere, o puede ser puntual, conforme al primer caso (perfección gramatical y real), de manera que ya no la quiere. Al modificar por toda la vida la ha querido con locura, el efecto de la acción de querer es relevante en el presente: si atañe al segundo caso (perfección gramatical y real), la ha querido hasta un momento del pasado, próximo o remoto; si atañe al tercer caso, todavía la quiere. Por lo visto, el contexto es determinante para saber si aún la quiere.

\section{Distinción entre algunas formas de la conjugación verbal}

En este artículo no cabe una distinción más minuciosa y completa entre las formas simples y las correlativas compuestas de la conjugación verbal -faltan las de subjuntivo, por ejemplo-. Nos atendremos a las de la tabla 1. Lo primero que se ha de notar es que entre cada pareja (amo y he amado, amé y hube amado, amaba y había amado) no hay distinción temporal, pero tampoco aspectual, a diferencia de lo que sostienen Alarcos y otros autores. En amo, el tiempo es presente y el aspecto es continuo, lo mismo que en be amado -según el auxiliar be-; en amé, pasado y discontinuo como en bube amado, y en amaba, pasado y continuo como en había amado. La particularidad, la distinción gramatical es que el participio de las formas compuestas expresa la acción como perfecta y asimismo anterior. Claro que amé la expresa como perfecta, pero se verá que bube amado es anterior.

\subsection{Distinción entre be amado y babía amado}

Estas formas compuestas son análogas. Mientras que be amado expresa una acción terminada cuyo efecto se siente en el presente, había amado expresa una acción terminada cuyo efecto se sentía en el pasado. En ambas formas la acción es perfecta o terminada, 
según el participio, pero el aspecto, por decirlo así, muestra de continuo el final de la acción, según los auxiliares be y había. No son, pues, distintas en el aspecto, sino solo en el tiempo: presente y pasado, respectivamente.

1. He entendido otra cosa, después de lo que dijiste.

2. Había entendido otra cosa, después de lo que dijiste.

En ambos ejemplos, el aspecto muestra de continuo el final de la acción de entender. Pero, en el primero, algún efecto de ella se siente en el presente; en el segundo, se sentía en el pasado.

Si bien con las formas be amado y babía amado se concibe la acción como gramaticalmente perfecta, ambas pueden implicar que ella siga durando realmente en el tiempo respectivo: presente y pasado. Por lo que a veces, según el contexto y dada su analogía, expresan la perfección gramatical, no real. En Juan ba sido médico desde 1980, el ser médico puede durar todavía en el presente; en Juan había sido médico desde 1980, podía durar aún en el pasado.

\subsection{Distinción entre amé y bube amado}

En cuanto a estas formas, repetimos que no hay distinción temporal ni aspectual: la acción es igualmente de tiempo pasado y de aspecto discontinuo. En ambos casos el aspecto no muestra de continuo el final de la acción. No se sentía en el pasado algún efecto de ella.

En este ejemplo, jugué cuando bubo llovido, ¿cuál acción es anterior, el jugar o el llover? De las dos se percibe igualmente el final: son perfectas. ¿No hay entre ellas distinción de anterioridad? Sí, el llover es anterior; terminó primero. Es explicable con este artificio gramatical para favorecer la comprensión: en jugaba cuando habia llovido, el llover es anterior, porque el aspecto muestra de continuo su final, mientras que del jugar muestra de continuo el intermedio. Una vez que el jugar llegue al final, será discontinuo: jugué cuando había llovido. Aun así, el llover será anterior. Seguirá siéndolo, una vez que el aspecto no muestre de continuo su final: jugué cuando bubo llovido. La duración entre el final del llover y el final del jugar es incierta, a menos que sea marcada con un complemento circunstancial de tiempo. Hube amado no puede ser, pues, del todo igual a amé. Se conoce también como el pretérito remoto. Sin duda, con respecto a amé es anterior, pero la distancia, según el caso, es próxima o remota.

Es anterior no por el tiempo ni el aspecto. Se insiste: lo que las distingue no es el tiempo -la acción pertenece igualmente al pasado- ni el aspecto -es igualmente discontinua-, sino la anterioridad: con la forma compuesta, dada su morfología, se expresa 
que la acción terminó primero en el pasado. Ya que son de tiempo pasado, es obvio que no se distinguen en el tiempo. ${ }^{14}$

\subsection{Simultaneidad, contemporaneidad y anterioridad}

Estos términos, simultaneidad, contemporaneidad y anterioridad, son extrínsecos a las formas verbales por depender de cierta relación temporal entre ellas -mediante alguna conjunción, por ejemplo, y según la consecutio temporum-. Para Guillermo Rojo \& Alexandre Veiga (1999), la simultaneidad es lo mismo que la coincidencia entre dos acciones. Pero se ha de precisar: la coincidencia en el mismo momento (cf. Vásquez González, 2015, pp. 205-209). En jugaba cuando llovió, no tal hay coincidencia. Ambas acciones son más bien contemporáneas, comparten un contenido temporal, en que el llover, discontinuo, precede al jugar, continuo -y, como falta el contexto, se ignora no solo la duración de ellas, sino cuál comenzó primero-. Sin duda, fueron simultáneas, coincidieron en el mismo momento, según que eran igualmente durativas -durante el intermedio-: jugaba cuando llovía, hasta que el llover cesó -llegó al final-: jugaba cuando llovió.

En jugaba cuando bubo llovido, ambas acciones comparten también un contenido temporal, en que el llover, discontinuo, precede al jugar, continuo -y, como falta el contexto, se ignora cuánto duró entre el final del llover y el intermedio del jugar-.

Nótese la diferencia entre llovió y bubo llovido, que expresan igualmente la acción como perfecta. Jugaba cuando llovió no significa lo mismo que jugaba cuando bubo llovido. En el primer caso, el llover, aunque ya es anterior, pudo ser simultáneo con el jugar; en el segundo, el llover siempre fue anterior, nunca simultáneo.

En jugaba cuando llovió se deduce que, después de la posible simultaneidad entre ambas acciones, el juego duraba. En jugaba cuando bubo llovido se colige que, después de la anterioridad de la lluvia, el juego duraba.

14 Se encuentran ejemplos literarios que entre sí comparan las formas amaba y había amado. Se resaltará con negrita los términos relacionados. «iY en qué momentos venía Satanás a turbar su espíritu, cuando se había puesto en paz con Dios, cuando había fortalecido su conciencia!» (Pérez Galdós, 1884/2002, p. 229). «Tal vez fue el contraste entre él y aquella mujercita que apenas le llegaba al hombro y parecía tener quince años cuando había cumplido los veinte» (Blasco Ibáñez, 1906-1919/1998, p. 214). «Pero sucedía que cuando había examinado tantas variantes enrevesadas, me olvidaba del orden de las preguntas y respuestas o las mezclaba, como sucede en el ajedrez cuando uno imagina partidas de memoria» (Sábato, 1948/1986, p. 74). «Mi hermana Candé estaba muy enferma del pasmo de sangre. Un viaje inútil. Recordaba el anterior, veinte años antes, cuando había ido con taitá a traer el bálsamo para el Karaí» (Roa Bastos, 1960/1977, p. 26). «En vano insistió Úrsula para que tirara la golilla de lana con que se levantaba cuando había hecho el amor, y que provocaba los cuchicheos de los vecinos» (García Márquez, 1967/1989, p. 188). Se observa que la acción expresada por las formas compuestas es anterior a la expresada por las simples, pero ambas pertenecen igualmente al tiempo pasado; además, las formas simples reclaman el copretérito (amaba), no el pretérito (amé), al querer reflejar un carácter durativo. Sin embargo, en este caso: «Cuando era más necesaria su presencia; cuando había dicho: "descuida que vendré sin falta", no parecía” (Pérez Galdós, 1883/2003, pp. 108-109), parecía puede modificarse por pareció, pero se expresa con el copretérito para resaltar la actualidad. 
Entre el final del llover y el intermedio del jugar se puede precisar, mediante un complemento circunstancial de tiempo, la duración, que es variable, no inmediata como tanto se ha repetido. Así, jugaba cuando bubo llovido dos boras antes. Reconozco que este ejemplo es de laboratorio, como tantos otros aquí, pero es tolerable gramaticalmente, incluso confrontable con la documentación histórica. ${ }^{15}$

\subsection{Distinción entre babía amado y bube amado}

Se dijo en $\S 1.5$ que con ambas formas compuestas la acción es igualmente perfecta, debido al participio, pero, según el auxiliar, hay entre ellas distinción aspectual: continuo y discontinuo, respectivamente, y no temporal: son igualmente de tiempo pasado.

Escribe Grijelmo (2007): «Entre el pretérito pluscuamperfecto [había amado] y el tiempo perfecto al que acompañe aquél puede haber un margen de tiempo mayor que entre el pretérito anterior [bube amado] y su acción verbal de referencia» (p. 250). No lo creo. No hay ningún margen de tiempo mayor o menor, a menos que sea marcado con un complemento circunstancial de tiempo. Veamos estos ejemplos, gramaticalmente verosímiles:

\section{Salí cuando habia llovido dos horas antes.}

2. Salí cuando bubo llovido dos horas antes.

En ambos, el margen de tiempo entre el final de la salida y el final de la lluvia es el mismo: dos horas. Lo que difiere no es el tiempo, sino el aspecto: en el primer caso, continuo, se sentía en el pasado el efecto de la acción de llover -era relevante-, no en el segundo, discontinuo. Sin duda, el llover es igualmente anterior al salir.

Tal vez sea más fácil y patente distinguir entre amaba, "imperfecto", y amé, "perfecto", que entre babía amado y hube amado, igualmente "perfectos", referidos al final de la acción. La funcionalidad del aspecto para el español actual, a mi juicio, es sostenible no solo entre esas formas simples, sino también entre esas compuestas: aunque son "perfectos" porque el participio expresa la acción terminada, difieren en el aspecto debido al auxiliar: con había amado, continuo, se sentía en el pasado -era tenido en cuenta- algún efecto de la acción, no con bube amado, discontinuo. Recordemos que los "perfectos" be amado y había amado son formas análogas, así como, considerando su valor primario, los "imperfectos" amo y amaba, referidos al intermedio de la acción.

15 Los ejemplos (diacrónicos y sincrónicos) que citan Álvaro S. Octavio de Toledo y Huerta \& Javier Rodríguez Molina (2008, p. 295; pp. 316-317) desmienten la hipótesis de que con la forma bube cantado se expresa siempre la inmediatez de la acción con respecto a otra. 
El oficio de he amado, según Caro (1976), «es denotar una acción pretérita en cuanto empezada en un momento pasado, pero presente en cuanto sus efectos se extienden hasta el momento en que se habla» (§ 26, pp. 46-47). Análogamente, el efecto de la acción de había amado se extendía hasta un momento del pasado, es decir, era relevante.

Veamos este fragmento literario de Coloma (1928): «Nosotros sonábamos como ricos, no millonarios, pero de buen capital; verdad es que lo habíamos tenido y que mi padre suplió con los ingresos que lograba lo que se hubo perdido de sus bienes» (p. 1358). Es evidente que la pérdida de los bienes es anterior a la suplencia con los ingresos, no simultánea; así que se evita por claridad la simple perdió o perdía. Si se sustituye bubo perdido por había perdido, el sentido podrá ser distinto, dada la diferencia aspectual entre ambas formas: con bubo perdido, discontinuo, se entiende que los bienes se perdieron del todo, antes de la suplencia con los ingresos; con babía perdido, continuo, no necesariamente del todo, pues, aunque la pérdida se concibe como gramaticalmente perfecta -también anterior a la suplencia y, sin duda, en el mismo momento del pasado que con bubo perdido-, podía seguir durando realmente mientras se iba supliendo. Aquí el aspecto continuo explica que el efecto de lo perdido continuaba en el pasado, era relevante durante la suplencia, tanto que podían seguir perdiéndose los bienes -se trataría de una perfección gramatical, no real, por la analogía de esta forma con be amado-. ${ }^{16}$

Releamos este fragmento de Sábato (1948/1989): «Pero sucedía que cuando había examinado tantas variantes enrevesadas, me olvidaba del orden de las preguntas y respuestas o las mezclaba, como sucede en el ajedrez cuando uno imagina partidas de memoria» (p. 74). No es lo mismo decir hube examinado que habia examinado, si bien con ambas formas se expresa igualmente la acción como perfecta y anterior en el mismo momento del pasado -aquí hay perfección gramatical y real, conforme al segundo caso: cf. § 1.7-: con el aspecto continuo se indica que el efecto del examinar las variantes se sentía en el pasado durante el olvido del orden de las preguntas y respuestas, lo que se omite con el aspecto discontinuo. Para entenderlo más, usemos el presente: cuando be examinado tantas variantes enrevesadas, me olvido del orden de las preguntas y respuestas. El examinar es anterior al olvidar. El hecho del examinar las variantes se siente en el presente, a la vez que el orden de las preguntas y respuestas se olvida.

16 Esta explicación, metodológicamente basada en la oposición entre continuo y discontinuo, es particular y consecuente. Otros autores siguen, en principio, su propio enfoque y terminología cuando comparan entre babía amado y bube amado (cf. Toledo y Huerta \& Rodríguez Molina, 2008, p. 34 ss. y García Fernández, 2008, p. 359 ss.). El objetivo de este artículo es llevar a cabo lo propuesto en la introducción; no es una revisión crítica de lo que tantos autores entienden por aspecto - diversas son las teorías y cuantiosas son las referencias-. Veiga (2015), adhiriéndose todavía al sistema vectorial de la temporalidad lingüística de Rojo y al propio sistema modal, tiene que concluir que el aspecto no es una categoría funcional independiente. Alarcos, defensor del aspecto, es aquí el gramático de más interés. 
Consignemos un ejemplo de Bello, donde se evidencia el raro uso de la forma bube amado como una oración independiente: «Casi hube creído que su conducta era franca y leal; pero al fin se quitó la máscara» (citado por Toledo y Huerta \& Rodríguez Molina, 2008, p. 346, n. 86). Concedamos que es más común decir creí o babía creído. Con estas tres maneras de tiempo pasado es correcto indicar igualmente la perfección y anterioridad de la acción frente al quitarse la máscara. Ateniéndonos a la morfología del auxiliar, bube creído y babía creído no son indiferentes: son formas distintas solo en el aspecto, no en el tiempo. Hayperfección gramatical, pero, por el condicionamiento del adverbio casi, no hay perfección real plena de la acción, sino parcial. Con había creído, algo se resalta: el efecto del creer en su buena conducta continuaba en el pasado, aún era sentida su franqueza y lealtad; con bube creído -lo mismo que con creí- es terminante: no se sospecharía ya de su falsedad.

Ahora bien, a fin de discernir la anterioridad entre había amado y bubo amado, analicemos este ejemplo de Toledo y Huerta \& Rodríguez Molina: «Cuando Paco hubo acabado, María ya había empezado» (citado por Toledo y Huerta \& Rodríguez Molina, 2008, p. 346, n. 86). Describen los autores que el empezar es anterior al acabar. Pienso que es discutible. Ambas acciones son perfectas o terminadas, según el participio, y asimismo se refieren al final. No se distinguen en el tiempo - pertenecen igualmente al pasado-, sino en el aspecto, según el auxiliar: había empezado es continuo, y bubo acabado, discontinuo; el primero muestra de continuo el final, no el segundo; en aquel se sentía el efecto de la acción, no en este. En mi opinión, aquí no hay manera de determinar la anterioridad: el adverbio ya sugiere que la duración entre el final del empezar y el final del acabar es pequeña, pero no aclara cuál acción es anterior o terminó primero.

A falta del contexto, no siempre es factible determinar la anterioridad entre las formas había amado y hube amado. Si se omite el adverbio ya-recurrente y enfático con babía amado-, todavía no se sabe cuál acción es anterior: cuando Paco bubo acabado, María había empezado. Es más, no se sabe cuál acción comenzó primero, pues ambas formas son compuestas y expresivas de lo perfecto, de lo que se refiere al final. De manera que, si realmente el acabar comenzó -y terminó- primero, conviene comparar con una forma simple: cuando Paco bubo acabado, María empezó -incluso cuando Paco babía acabado, María empezó-. A diferencia de lo que sostienen algunos, de estos ejemplos se ha de advertir -como se vio en $\S 2.3-$ que ambas acciones nunca fueron simultáneas: el acabar fue siempre anterior. Lo cierto es que la precisión del contexto -en este caso, los complementos temporales- puede determinar la anterioridad: cuando Paco bubo acabado, María había empezado dos horas antes -aquí el empezar es anterior-, o al 
contrario: cuando Paco bubo acabado, María había empezado dos horas después -aquí el acabar es anterior-.

\subsection{Sobre bube amado: la anterioridad, no la inmediatez}

Muchos gramáticos han opinado lo mismo sobre bube amado, denominado pretérito anterior. Lo resume Cartagena (1999): «Este tiempo significa anterioridad inmediata a una acción pasada respecto del momento del habla, por lo cual va normalmente introducido por cuando, apenas, así que, enseguida que, no bien, tan pronto como» (p. 2951). Pero la acción no tiene por qué ser inmediatamente anterior a otra, a menos que un complemento circunstancial de tiempo lo especifique. Sin duda, la inmediatez se desprende del (ab)uso de ciertos adverbios o locuciones adverbiales, no del solo pretérito anterior. Como Toledo y Huerta \& Rodríguez Molina (2008), ya Luis García Fernández (2008) desmiente que con hube amado se expresa siempre la inmediatez.

Parece que se debe a la autoridad de Bello la repetición de lo que expresa esa forma. Dice: «Significa que el atributo es inmediatamente anterior a otra cosa que tiene relación de anterioridad con el momento en que hablo. "Cuando hubo amanecido, sali": el amanecer se representa como inmediatamente anterior al salir, que es cosa pasada respecto del momento en que se habla» (Bello, 1847/1948, § 640). Luego pregunta: «ipor qué como inmediatamente anterior?» (§ 641). Argumenta así: «Proviene, a mi juicio, de que el verbo auxiliar haber es de la clase de los permanentes. Cuando bubo amanecido denota el primer momento de la existencia perfecta de haber amanecido» (§ 641).

No es muy convincente. El auxiliar no aporta aquí mucho sentido léxico. Además, si bien el amanecer es perfecto, no se deduce que la salida es inmediatamente posterior. Bello no es exacto al afirmar que cuando bubo amanecido, sali = luego que amaneció, salí y que es un pleonasmo luego que bubo amanecido, salí. No es un pleonasmo: con bubo amanecido, se salió después de la anterioridad del amanecer. ${ }^{17}$

Para aclararlo más, convirtamos al aspecto continuo: cuando amanecía, (yo) salía. Ambas acciones, el amanecer y el salir, coincidían, eran simultáneas -por suceder igualmente durante el intermedio-, hasta que cesó la salida: cuando amanecía, salí.

17 Ya Cuervo anotó: «En los tiempos anteclásicos hube cantado era comunísimo en lugar de canté, y al parecer sin indicar ninguna de las ideas accesorias que apunta [Bello]» $(1948, \S 93)$. De la expresión en lugar de no se colige con exactitud que entre canté y bube cantado hay «equivalencia completa», como escribe Gili Gaya (1943/1981, § 125, p. 163, n. 5). Además, Cuervo corrige a Bello: el auxiliar haber «va perdiendo su sentido concreto de tener, hasta convertirse en mero signo formal sin más valor que tendría un sufijo; [...] el participio, emancipándose del sustantivo, representa tan sólo la raíz verbal» (1948, § 71). En este ejemplo de Miguel de Cervantes: «pero no hubo llegado [don Quijote] a las paredes del corral, que no eran muy altas, cuando vio el mal juego que se le hacía a su escudero» (1605/1998, p. 184), el no llegar es anterior al ver, porque se usa la forma compuesta, no la simple llegó. 
Se deduce que después de la simultaneidad entre ellas, el amanecer duraba, hasta que también cesó: cuando amaneció, salí. Ahora bien, en este ejemplo, cuando bubo amanecido, sali, el amanecer, próximo o remoto, siempre fue anterior al salir, nunca simultáneo -para entenderlo mejor, cf. § 2.2-. Por esto repito que se salió después de la anterioridad del amanecer. Así se demostraría que ambas formas (amé y bube amado) no son propiamente sustituibles, alternables o equivalentes.

Gili Gaya (1943/1981) dice una cosa diferente: Bello cree «que no hay pleonasmo en decir cuando bubo amanecido, sali porque cuando no significa sucesión inmediata» (§ 125). ¿Entonces qué la expresa? Gili Gaya, de acuerdo con Bello, reitera que bubo amanecido es sustituible por luego que amaneció: «la sucesión inmediata la expresa el adverbio [luego]» (§ 125). Aquí hay una confusión. Es cierto que tal adverbio puede entenderse como prontamente, sin dilación, conforme a la primera acepción de la RAE, pero no necesariamente bubo amanecido se parafrasea como luego que amaneció. Más bien como después que amaneció. Añade Gili Gaya: «En el uso del idioma la diferencia entre cuando amaneció salí y cuando hubo amanecido sali es tan poco perceptible en lo que se refiere a lo inmediato de las dos acciones, que podemos decir que con cualquiera de los adverbios enumerados se consigue el mismo efecto» (§ 125).

La diferencia no es poca y no se consigue lo mismo. Al respecto, menciono un ejemplo de Cartagena (1999): cuando bubo prendido fuego al porro, se lo pasó a la mujer (p. 2951). Según el autor, prendió y había prendido pueden ser sinónimos de bubo prendido. No es cierto. Con bubo prendido se entiende un antes y un después: primero se prendió fuego, luego se pasó el porro. Si bubo prendido se neutraliza con prendió: cuando prendió fuego al porro, se lo pasó a la mujer, se puede inferir que el prender y el pasar fueron a la vez. Para comprobarlo, usemos el aspecto continuo: cuando prendía fuego al porro, se lo pasaba a la mujer. Así ella se quemaría. Incluso así: cuando prendió fuego al porro, se lo pasaba a la mujer. Por el "desuso" de bubo prendido, es preferible babía prendido, si aún se quiere expresar un antes y un después: cuando había prendido fuego al porro, se lo pasó a la mujer.

La diferencia entre habia prendido y bube prendido es aspectual: hube prendido es discontinuo. Con babía prendido, era relevante el efecto del prender -es análogo al tiempo presente: cuando ha prendido fuego al porro, se lo pasa a la mujer-. Si no se quiere usar las formas compuestas, sino la simple, la conjunción cuando se evita entonces: después que prendió fuego al porro, se lo pasó a la mujer. ${ }^{18}$

18 La forma hube amado se estima hoy desusada (Rojo \& Veiga, 1999). Sin embargo, no significa que no pueda ni deba usarse más. Comenta Camus Bergareche (2008): «Se trata de una forma prácticamente desaparecida de la lengua hablada moderna y sus 


\subsection{Distinción entre amaba y amé}

Ambas formas simples no se distinguen en el tiempo, sino en el aspecto. Son igualmente de tiempo pasado, pero de aspecto continuo y discontinuo, respectivamente. Con la forma amaba, el aspecto muestra de continuo el intermedio de la acción: se sentía en el pasado la duración de ella. Por concebirse aún no terminada, es imperfecta. Es análoga a la forma amo, cuyo aspecto muestra también de continuo el intermedio de la acción: se siente en el presente la duración de ella. Con la forma amé, por el contrario, el aspecto no muestra de continuo su final. Es gramaticalmente perfecta, aunque pueda no ser en ocasiones realmente perfecta.

En este controvertido ejemplo que recoge Veiga (2015): observaron borrorizados que la bomba hacía explosión dos minutos antes de lo previsto (p. 124), el aspecto de hacía es continuo, a pesar de que este autor, revisando las gramáticas tradicionales, se empeñe en negar aquí su cualidad de "imperfecto" o de "durativo". Si bien la observaron (simple perfección gramatical, no necesariamente real), se resalta el intermedio de la explosión, después de comenzar y antes de terminar, es decir, su duración, por más instantánea que sea. Es distinto la bomba bizo explosión, en que el aspecto es discontinuo: se percibe su final, después de terminar. Hizo y hacía no expresan una diferencia de tiempo -pues pertenecen igualmente al pasado-, sino de aspecto.

En otro ejemplo: al amanecer salió el regimiento, atravesó la montaña, y poco después establecía contacto con el enemigo (Veiga, 2015, p. 125), se notan tres sucesos: salió, atravesó y establecía, con la diferencia de que en los dos primeros se percibe el final de la acción y el aspecto es discontinuo, en tanto que en el último se resalta su intermedio y el aspecto es continuo. Es más que un recurso estilístico: para expresar el contacto con el enemigo como durando en el pasado se ha de usar la forma simple establecía, no estableció, sencilla interpretación que no dista mucho de ser tradicional, pero que un autor como Veiga (2004a, pp. 169-70; 2004b, § 2.2; 2008, § 11.3.1; 2015, p. 125) tal vez cuestione. $^{19}$

usos, casi siempre antiguos y literarios, tienden a solaparse con los del perfecto simple [amé]» (p. 88). García Fernández (2008): «mientras que el pretérito pluscuamperfecto [había amado] se mantiene perfectamente vivo, el pretérito anterior [bube amado] es una forma en desuso, con una sintaxis limitada a las oraciones subordinadas temporales» (p. 359). Para un lectura más profunda sobre este tiempo compuesto, cf. el excelente texto de Toledo y Huerta \& Rodríguez Molina (2008), quienes afirman: «Desde siempre, bube cantado fue una forma altamente especializada y de uso escritural» (p. 307). Cabe anotar que, según ellos, entre amé y bube amado no hay diferencia temporal, sino aspectual (p. 319). Sin embargo, en otro discurso argumentativo, considero que no la hay de tiempo -pertenecen igualmente al pasado- ni de aspecto -expresan igualmente la acción como discontinua-, sino de prioridad en cuanto se relacionan: hube amado es anterior.

19 Cf. Vásquez González (2015, pp. 205-209) sobre el problema de la denominación bellista de copretérito. Para Veiga expresa simultaneidad, como para Bello coexistencia (2015, p. 127; p. 137, n. 30); Vásquez González critica esta sinonimia. 


\subsection{Distinción entre amé y be amado}

Afirma Alarcos (1970/1984): «con la forma compuesta [he amado] el límite de la acción es el presente, con la simple [amé] un punto del pasado» (p. 28). No siempre con la compuesta el límite de la acción es el presente, pues puede ser, también como la simple, algún momento del pasado, próximo o remoto. Propiamente, no es el límite de la acción, sino de algún efecto suyo, que se extiende hasta el presente-perfección gramatical y real, según vimos en el segundo caso: cf. § 1.7-. Mejor dicho, el presente implica algún efecto de ella. Es así explicable que algunos gramáticos hayan hablado del contenido "psicológico", "subjetivo" o "afectivo" de he amado -lo mismo vale para la compuesta había amado: algún efecto de la acción se extendía hasta un momento del pasado, lo que no expresa bube amado, cuyo efecto no se sentía o no era relevante, a semejanza del uso con amé-. Con razón Alarcos la denominó el «presente ampliado» (hacia el pasado): implica el segmento temporal entre el presente y el momento del pasado en que termina la acción. ${ }^{20}$

Por otra parte, amé y he amado no siempre expresan laperfección real de la acción, sino solo la perfección gramatical -según vimos en el tercer caso: cf. § 1.7-. Con ambas formas la acción se concibe como gramaticalmente perfecta, aunque siga durando realmente en el presente. Por ejemplo, la Tierra giró alrededor del sol, la Tierra ha girado alrededor del sol (Vásquez González, 2015, p. 209). No son indiferentes: con giró, el tiempo es pasado y el aspecto es discontinuo; con ha girado, el tiempo es presente y el aspecto es continuo.

Para Escarpanter (1994), he amado y amé son de aspecto perfecto: «La oposición no es, por tanto, aspectual, sino temporal, pero desde un punto de vista subjetivo» (p. 155). A mi modo de ver, la oposición es temporal y aspectual: he amado es de tiempo presente y de aspecto continuo, según el auxiliar he, y amé, de tiempo pasado y de aspecto discontinuo. Por supuesto, la acción en ambos ejemplos es perfecta o terminada. Escarpanter se habría basado en Alarcos (1970/1984), quien dice lo mismo: «leí un libro frente a be leído un libro indica un mayor alejamiento de la acción con respecto al punto de vista del que habla, pero en los dos casos el aspecto de la acción es el mismo: perfectivo» (pp. 1920). No necesariamente un mayor alejamiento; en ambos casos, desde luego, la acción es gramatical y realmente perfecta; en el mismo momento, si se les añade una misma frase adverbial, como esta mañana; pero la diferencia entre leí y he leído no es solo temporal,

20 Para Caro (1976), he amado es el cuasi-presente: «su oficio es denotar una acción pretérita en cuanto empezada en un momento pasado, pero presente en cuanto sus efectos se extienden hasta el momento en que se habla» (\$ 26, pp. 46-47). Con un enfoque algo descriptivo, textos breves y aleccionadores sobre los usos distintos de ambas formas es el de Almeida (1987-1988) y de Moreno de Alba (2003). Valioso, con un enfoque más teórico, es el apartado de Veiga $(2015, \S 5)$ sobre su estado de la cuestión. 
sino aspectual. Precisamente porque se distinguen en el aspecto, la forma compuesta es el "presente ampliado". ${ }^{21}$

Veiga (2015, p. 135), siguiendo a Porto Dapena (1989, § III.1.1), explica que, en este ejemplo: siento comunicarte que tu amigo ba muerto, el morir, "perfecto", no se percibe como temporalmente "presente", pero aquí entendemos que es relevante -como cosa reciente en este caso- su efecto en el momento del habla: el aspecto es continuo porque continúa en el presente el sentimiento de la noticia de su muerte, lo que gramaticalmente no dice siento comunicarte que tu amigo murió -aunque sean correctas ambas formas y semánticamente designen lo mismo-. Y en este ejemplo: ¿pero te enteras ahora de que siempre be vivido en este barrio?, explica Veiga (2015, p. 135), siguiendo también a Porto Dapena, que be vivido no expresa la acción como "perfecta", pero aquí entendemos, por el contrario, que sí la expresa por tratarse de una perfección gramatical, no real y que además el aspecto es continuo: se resalta en el presente el hecho de vivir ahí. Es discontinuo con ¿pero te enteras abora de que siempre viví en este barrio?, que puede referirse, según el contexto, a una perfección gramatical, no real: aún vive ahí, o bien a una perfección gramatical y real -si añadimos siempre viví en este barrio durante mi niñez-: ya no vive ahí.

Carrasco Gutiérrez (2008) recoge, según una perspectiva histórica y comparativa, cuatro fases o maneras de expresión de be amado (p. 16), y enfatiza en la anterioridad de esta forma con respecto a amo. No obstante, su interpretación es aparte: sigue usando el término perfecto como una cualidad del aspecto, no como la simple expresión de la acción terminada. Es más, entre Juan ha escrito la carta a las tres y Juan ya ha escrito la carta (p. 16), dice que la forma compuesta del primer ejemplo es antepresente (anterioridad en términos temporales), y la del segundo, presente (anterioridad en términos aspectuales), pero, a mi parecer, ambas formas no se distinguen en el tiempo (presente) ni en el aspecto (continuo); hay solo una diferencia extrínseca de sentido: el final de la acción del primero -debido al complemento temporal: a las tres-implica un mayor alejamiento con relación al del segundo.

21 La explicación no se distancia mucho de la de Comrie (1981). Para este autor, he amado y amé no difieren en el tiempo, pues pertenecen al pasado, sino en el aspecto: con la forma compuesta, lo pasado continúa teniendo relevancia en el presente. Esto es razonable, si se atiende a que el final de la acción en ambos casos es anterior al presente. Sin embargo, he amado es gramaticalmente presente no por la duración de la acción -que sin duda pertenece al pasado, próximo o remoto, y es anterior al presente-, sino por el sentimiento de algún efecto suyo. En otras palabras, es el tiempo presente no de la acción, sino del efecto de ella. 


\section{Conclusión}

En sí mismo, el participio, siempre de género y número invariables (masculino y singular) en la forma compuesta de la conjugación verbal española, no expresa el tiempo ni el aspecto; el auxiliar haber los expresa. Solo explica la idea de la acción perfecta o terminada, sea cual fuere el tiempo: en el pasado, el presente o el futuro (por ejemplo, había amado, he amado o babré amado). Las cualidades tradicionales del aspecto (perfecto $\mathrm{e}$ imperfecto), procedentes de la terminología latina y aun de la griega, no son precisas ni consistentes, por lo visto, para distinguir entre las formas compuestas habia amado y bube amado. Convendría, pues, por exactitud aplicar las cualidades continuo y discontinuo y a la vez entender que lo perfecto designa una acción terminada, y lo imperfecto, no terminada.

La anterioridad no es un accidente verbal intrínseco, sino que es algo extrínseco: depende de cierta relación temporal -mediante una conjunción como cuando, respetada la consecutio temporum - entre dos acciones diferentes. En este caso, no es una noción aspectual ni temporal, sino correlativa. Se puede decir que una acción perfecta es anterior a otra y, por lo tanto, pasada. Pero esta última palabra se ha de entender con cautela: como terminada y no necesariamente como perteneciendo al tiempo pasado. En iré cuando hayas llegado a tu casa, el llegar, perfecto y asimismo anterior y pasado con respecto al ir, pertenece al tiempo futuro.

El aspecto, por el contrario, es un accidente verbal intrínseco -consecutivo de cierto morfema, aun cuando coincida con el de tiempo (Hernández Alonso, 1984/1996, pp. 458-459)-, e independiente del aspecto léxico y del sintáctico. Implicando un matiz "psicológico", se refiere al estado de la acción, el cual es triple:

1. El principio, antes de comenzar: para las formas simples de futuro, amaré y amaría, que expresan la acción aún no durativa -como explicaremos más adelante, pues estas formas no se incluyeron en la tabla 1-. El aspecto muestra de continuo el principio de ella.

2. El intermedio, después de comenzar y antes de terminar: para las formas simples amo y amaba, que expresan la acción aún durativa. El aspecto muestra de continuo el intermedio de ella.

3. El final, después de terminar: para todas las formas compuestas y la simple amé, que expresan la acción ya no durativa. El aspecto muestra de continuo el 
final de ella (para be amado y había amado) o no lo muestra de continuo (para bube amado y amé). ${ }^{22}$

El aspecto se refiere, pues, al estado de la acción, no al tiempo de ella: no es un derivado del tiempo. Repetimos que las cualidades del aspecto son dos: continuo y discontinuo. Son la consecuencia de precisar las tradicionales perfecto e imperfecto. Sin embargo, continuo no significa durativo. Se ha de advertir que durativo y no durativo no son aquí las cualidades del aspecto, equivalentes a imperfecto y perfecto 0 a no terminativo y terminativo. La forma habia amado, por ejemplo, es de aspecto continuo, pero no durativa: refiriéndose al final de la acción, se sentía su efecto en el pasado. La acción no continuaba, sino su efecto. Análogamente, la forma be amado es de aspecto continuo, pero tampoco durativa: refiriéndose también al final de la acción, se siente su efecto en el presente. La acción no continúa, sino su efecto. Cierto es que a veces la perfección gramatical no es real (cf. § 1.7).

Por lo precisado, ya el concepto de aspecto ha sufrido una mutación y se presume que no es común entre los lingüistas. Pues no se infiere, como han sostenido algunos, solo de distinguir entre las formas simples amé y amaba, sino entre las compuestas hube amado y había amado, pese a la limitación en las aplicaciones sintácticas y al insistente desuso, recesión o infrecuencia de bube amado -que muchos recomiendan omitir del paradigma del sistema verbal del español actual-. Aquí se trajo a colación, como un ejercicio teórico, para notar la diferencia aspectual con habia amado y además su irreductibilidad a amé. ${ }^{23}$ En mi opinión, bube amado puede todavía pertenecer al sistema. La razón es ser la pareja correspondiente de amé, así como había amado lo es de amaba. Esta relación simétrica se justifica por el hecho de la mencionada diferencia aspectual y también por la noción (extrínseca) de anterioridad con respecto a amé. ${ }^{24}$

Otro asunto es el problema terminológico de la denominación de cada forma verbal, leída la nomenclatura de la conjugación de la RAE. Algunos autores se han sentido inconformes por no ser tan exacta, como Alarcos (1994/2000, § 220). Pero hasta la de

22 La segunda acepción del DRAE sobre duración es apropiada aquí: «Tiempo que dura algo o que transcurre entre el comienzo y el fin de un proceso» (cita de la 22. ${ }^{a}$ edición de la versión electrónica del diccionario disponible en Internet. Fecha de consulta: 12 de febrero de 2015). La duración corresponde siempre al intermedio de la acción.

23 Toledo y Huerta \& Rodríguez Molina (2008, pp. 283-285) mencionan las dificultades de los gramáticos (antiguos y modernos) sobre la clase de relación entre amé y hube amado. Por lo visto aquí, equivalen en expresar la acción como perfecta y también en la discontinuidad del aspecto, pero no son propiamente sustituibles.

24 García Fernández (2008) observa que bube amado no siempre expresa anterioridad, sino posterioridad. Depende. En este ejemplo: mucho tiempo después, cuando bube estudiado la carrera, estuve sin empleo, es claro que el estudiar sigue siendo anterior al estar, aunque se refiere -por el adverbio después- a un pasado posterior a otro. Hube amado, con respecto a amé, siempre es anterior. 
Bello, más elegante, tampoco es del todo exacta, según se infiere de Caro (1976, § 26, p. 47, n. 20), de Moreno de Alba (2006, p. 13) y de Vásquez González (2015, pp. 211-217).

Valga consignar esta tabla compendiosa, que recoge las formas verbales de la tabla 1 (en la primera conjugación, la primera persona y el número singular):

Tabla 2. Tiempo, aspecto y estado de las formas verbales de indicativo de la tabla 1

\begin{tabular}{|c|c|c|c|}
\hline Forma verbal & Tiempo & Aspecto & Estado \\
\hline amo & presente & continuo & intermedio \\
\hline he amado & presente & continuo & final \\
\hline amaba & pasado & continuo & intermedio \\
\hline había amado & pasado & continuo & final \\
\hline amé & pasado & discontinuo & final \\
\hline hube amado & pasado & discontinuo & final \\
\hline
\end{tabular}

Sea dicho de paso: en cuanto a las formas simples de futuro, amaré y amaría, el estado es el principio: la acción no ha comenzado aún -debido al infinitivo amar-. Amaré = be de amar y amaría = había de amar, como de antiguo se expresaba (Cuervo, 1993, pp. 8, 11): por los auxiliares be y había -unidos al infinitivo simple amar para la contracción definitiva-, el aspecto sería continuo. Con tales formas simples se imagina 0 presiente la acción (en el presente o en el pasado) como llegando a comenzar más tarde o más temprano. La acción no continúa o continuaba, sino su posibilidad o causa (imaginada o presentida), por decirlo así.

De manera semejante se explicará con las formas compuestas de futuro: en babré amado y habría amado, el estado es el final: la acción es terminada-debido al participio-. Habré de amar = he de haber amado y habría de amar = había de haber amado: por los mismos auxiliares be y había - unidas al infinitivo compuesto haber amado-, el aspecto sería también continuo. Con tales formas compuestas - no distintas en el aspecto ni el estado, sino en el tiempo- se imagina o presiente la acción (en el presente o en el pasado) como terminada. La acción no continúa o continuaba, sino su efecto (imaginado o presentido). En babré amado, el aspecto muestra de continuo el final de la acción, después de terminar, mientras que en amaré muestra de continuo su principio, antes de comenzar; lo mismo se colegirá entre babría amado y amaría. 
Ahora bien, para un próximo artículo -donde han de incluirse todas las formas de indicativo, de potencial y de subjuntivo-, se bosqueja que el estado puede ser un nuevo accidente verbal, funcionalmente independiente del tiempo y del aspecto y hasta con una morfemática particular localizada también en las formas no personales: el infinitivo (-r) y el participio $(-d-)$. El morfema del gerundio (-nd-) sería un alomorfo equivalente en relación con el morfema de aspecto de las formas simples de estado intermedio: amo y amaba. Un ejemplo: en había amado, el participio da el morfema de estado, para expresar el final de la acción, y el auxiliar, el común de tiempo y aspecto, para expresar, además de lo pretérito, la continuidad de algún efecto de la acción.

Es comprobable que el morfema de estado no es siempre igual al de aspecto. El concepto de estado no parece una inflación terminológica: se desprende del objetivo de analizar y precisar el concepto de aspecto en el ámbito restringido de la lengua española. Según la tabla 2, difieren los rasgos: entre amo y he amado, el aspecto es el mismo, continuo, también el tiempo, presente, pero el estado es diverso: intermedio y final. Es más, entre amo y amaba, el estado es el mismo, intermedio, también el aspecto, continuo -pues la acción continúa durante el intermedio-, pero el tiempo es diverso: presente y pasado -ateniéndonos al valor primario de ambas formas- $-{ }^{25} \mathrm{Y}$ entre amaba y amé no hay distinción temporal -pertenecen igualmente al pasado-, sino aspectual y estatal, mientras que entre babía amado y bube amado no la hay temporal ni de estado -son igualmente de tiempo pasado y de estado final-, sino solo aspectual.

Este artículo contribuye a la siguiente comprensión: el aspecto no consiste en atender a si dura o no dura la acción, sino precisamente en percibir si continúa 0 no continúa: 1) la duración de la acción, 2) el efecto de la acción, 3) la causa de la acción. Gramaticalmente, en el primer caso tenemos los "imperfectos", relativos al intermedio: las formas simples amaba y amo; en el segundo, los "perfectos", relativos al final: todas las formas compuestas y la simple amé; y en el tercero, los también "imperfectos", relativos al principio: las formas simples de futuro, amaré y amaría.

El aspecto y el estado son, pues, conceptos distintos e irreducibles entre sí, aunque relacionables: el uno incluye el otro. Ahora podemos definir:

- El estado es lo que señala las fases de la acción: el principio, el intermedio o el final.

25 Hay casos de excepción. En este ejemplo de Bello (1931): «Yo iba ayer al campo, pero amanecí indispuesto, y tuve que diferir la partida» (§ 127), iba simula la forma iría, de modo que adopta un valor temporal secundario: futuro. La acción de ir no se percibe en el intermedio, sino en el principio, y asimismo es potencial o irreal. Sobre los usos secundarios de las formas verbales, cf. Vásquez González (2015). Aquí nos hemos atenido a ellas en su valor primario. 
- El aspecto es lo que muestra el estado de la acción. Sus cualidades son continuo y discontinuo.

El aspecto no muestra únicamente el intermedio de la acción o su final, como dice Holt (1943), citado por Alarcos (1970/1984), sino su principio. Estoy de acuerdo con García Fernández (1998) en que el aspecto, a diferencia del tiempo, es una categoría verbal no deíctica: no localiza la acción en un momento anterior, interior o posterior al habla, sino que muestra el estado de ella con independencia del tiempo. Algo similar escribía Montserrat Veyrat Rigat (1993):

Desde el plano conceptual, en principio consideraremos el aspecto como una categoría gramatical que se distingue de las demás que contiene el verbo porque se refiere a la consideración por parte del sujeto de la acción en sí misma frente a la temporalidad, que marca el momento de la línea cronológica del tiempo en que el sujeto sitúa esa misma acción (p. 38).

Se ha de aclarar que el aspecto continuo no muestra solo el intermedio de la acción - esto es, la acción continúa durante el intermedio: después de comenzar y antes de terminar, lo que equivale propiamente a la duración-; puede mostrar también el final continúa el efecto de ella, después de terminar- o el principio -continúa su causa, antes de comenzar-. El aspecto discontinuo concierne solo a dos formas, amé y bube amado, cuyo estado es el mismo, el final: no continuaba el efecto por no sentirse o no ser relevante. Valga advertir que, según muchos autores, una forma como había amado es de aspecto perfecto. Pero aquí se dice continuo; lo perfecto solo se refiere al estado: el final de la acción.

Se evidencia que aquí el aspecto se separa de la tradición al sufrir una desvalorización conceptual. Cabría, por lo demás, proponer tres cualidades del estado: inactual, para el principio; actual, para el intermedio, y posactual, para el final. Lo inactual y lo actual se corresponden, conforme a la terminología de la gramática latina, a lo imperfecto, y lo posactual, a lo perfecto. Así puede haber un acuerdo. ${ }^{26}$

26 Gili Gaya (1943/1981): «Con verbos perfectivos [se] expresa la anterioridad de toda la acción; con los imperfectivos, la anterioridad de la perfección» (§ 122). Los perfectivos (perfectos) son posactuales: se percibe el final de la acción, después de terminar; los imperfectivos (imperfectos), actuales e inactuales: se percibe el intermedio, antes de terminar, o el principio, antes de comenzar. Todos los tiempos compuestos son ya no durativos por ser de estado posactual. No obstante, en un ejemplo como el de James Champion (1973, p. 1043): «reparó la máquina y después funcionó bien», se dirá que con funcionó no se indica la acción como posactual, dado que la máquina podía continuar funcionando. Aclaramos que con esta forma se expresa laperfección gramatical, no real. Es posactual, pues funcionó en un momento del pasado, aunque pudiese continuar funcionando desde entonces o en algunos momentos después de apagarse. Sobre el pretérito indefinido, cf. Vásquez González (2015, pp. 205-209). 


\section{Referencias bibliográficas}

Alarcos Llorach, E. (1970/1984). Estudios de gramática funcional del español (3a ed.). Madrid: Gredos.

Alarcos Llorach, E. (1994/2000). Gramática de la lengua española (2a reimpr.). España: Espasa Calpe.

Almeida, M. (1987-1988). Perfecto simple y perfecto compuesto en el español de Canarias. Revista de Filología, (6-7), 69-77. San Cristóbal de La Laguna, Tenerife: Universidad de la Laguna.

Bello, A. (1931). Análisis ideológica de los tiempos de la conjugación castellana. En: Obras completas, tomo 5. Estudios gramaticales, cap. 1, pp. 1-67. Caracas: Ministerio de Educación. Prólogo sobre las ideas ortográficas de Bello por Ángel Rosenblat.

Bello, A. (1847/1948). Gramática de la lengua castellana. Buenos Aires: Ediciones Anaconda.

Bertinetto, P. M. (1986). Tempo, aspetto e azione nel verbo italiano. Il sistema dell'indicativo. Firenze: L'Accademia della Crusca.

Blanco Hernández, P. (2005). Verbos españoles (2a ed.). Málaga: Arguval.

Blasco Ibáñez, V. (1906-1919/1977). La maja desnuda. Madrid: Cátedra.

Bosque, I., \& Demonte, V. (Dirs.) (1999). Gramática descriptiva de la lengua española. Madrid: Espasa Calpe.

Bybee, J., Perkins, Revere \& Pagliuca, W. (1994). The evolution of grammar: Tense, aspect, and modality in the languages of the world. Chicago \& London: The University of Chicago Press.

Camus Bergareche, B. (2008). El perfecto compuesto (y otros tiempos compuestos) en las lenguas románicas. Formas y valores. En: Á. Carrasco Gutiérrez. (Ed.). Tiempos compuestos y formas verbales complejas (pp. 65-100). Madrid y Frankfurt am Main: IberoamericanaVervuert.

Caro, M. A. (1976). Tratado del participio. Bogotá: Instituto Caro y Cuervo.

Carrasco Gutiérrez, Á. (2008). Los tiempos compuestos del español: formación, interpretación y sintaxis. En: Á. Carrasco Gutiérrez (Ed. $\left.{ }^{a}\right)$. Tiempos compuestos y formas verbales complejas (pp. 13-64). Madrid y Frankfurt am Main: Iberoamericana-Vervuert.

Cartagena, N. (1999). Los tiempos compuestos. En: I. Bosque \& V. Demonte (Dirs.). Gramática descriptiva de la lengua española (vol. 2) (pp. 2935-2975). Madrid: Espasa Calpe.

Cervantes, M. de (1605/1998). El ingenioso bidalgo don Quijote de la Mancha. Barcelona: Instituto Cervantes \& Crítica. 
Champion, J. (1973). Imperfect vs. preterit: A not-so-new approach. Hispania, 56(4), 1043-1044. Walled Lake, Michigan: American Association of Teachers of Spanish and Portuguese.

Coloma, J. (1928). La lucha. Barcelona: Sociedad General de Publicaciones.

Colombo Airoldi, F. (2004). El uso del perfecto en el español. En: G. Báez \& E. Luna Traill (coords.). Disquisiciones sobre filología hispánica. In memoriam Juan M. Lope Blanch (pp. 85-94). México: UNAM.

Comrie, B. (1976). Aspect. An introduction to the study of verbal aspect and related problems. Cambridge: Cambridge University Press.

Comrie, B. (1981). On Reichenbach's Aproach to Tense. En: R. A. Hendrick, C. S. Masek \& M. F. Miller (Eds.). Papers from the Seventeenth Regional Meeting (pp. 24-30). Chicago: Chicago Linguistic Society.

Cuervo, R. J. (1948). Notas a la gramática de la lengua castellana de don Andrés Bello. Buenos Aires: Ediciones Anaconda.

Cuervo, R. J. (1993). Diccionario de construcción y régimen de la lengua castellana (tomo V: H-J). Santafé de Bogotá: Instituto Caro y Cuervo.

Escarpanter, J. (1994). Cómo dominar la gramática. Introducción a la moderna gramática española. Bogotá: Norma.

Esteves, A. L. (2004). Algunos apuntes sobre temporalidad y aspecto verbal en español. Caligrama: Revista de Estudos Românicos, 9, 7-28. Belo Horizonte: Universidade Federal de Minas Gerais.

Fuentes de la Corte, J. L. (2005). Gramática moderna de la lengua española. Barcelona: Bibliográfica Internacional.

García Fajardo, J. (2011). He esperado, he vuelto, he vivido: su valor semántico en el español de México. Nueva Revista de Filología Hispánica, 59(2), 419-446. México: Centro de Estudios Lingüísticos y Literarios.

García Fernández, L. (1998). El aspecto gramatical en la conjugación. Madrid: Arco Libros.

García Fernández, L. (2008). Pretérito pluscuamperfecto y pretérito anterior. En: Á. Carrasco Gutiérrez (Ed.). Tiempos compuestos y formas verbales complejas (pp. 359-401). Madrid y Frankfurt am Main: Iberoamericana-Vervuert.

García Fernández, L., \& Camus Bergareche, B. (Eds.) (2004). El pretérito imperfecto. Madrid: Gredos.

García Márquez, G. (1967/1989). Cien años de soledad. Caracas: Ayacucho. 
García Martín, J. M. (2001). La formación de los tiempos compuestos del verbo en español medieval y clásico. Aspectos fonológicos, morfológicos y sintácticos. Valencia: Universidad de Valencia, Facultad de Filología.

Gili Gaya, S. (1943/1981). Curso superior de sintaxis española (12a ed.). Barcelona: Vox.

Grijelmo, Á. (2007). La gramática descomplicada. Bogotá: Taurus.

Guzmán Tirado, R., \& Herrador del Pino, M. (2002). El aspecto verbal en español: historia de la cuestión y nuevas aportaciones a su estudio. Santiago, (96), 27-45. Santiago de Cuba: Universidad de Oriente.

Hernández Alonso, C. (1984/1996). Gramática funcional del español. Madrid: Gredos.

Holt,J. (1943). Etudes d'aspect. Acta Jutlandica, 15(2). Aarhus, Danmark: Aarhus Universitetsforlag.

Lubbers Quesada, M., \& Maldonado, R. (Eds.) (2005). Dimensiones del aspecto en español. México: UNAM, Instituto de Investigaciones Filológicas.

Martínez Atienza, M. (2014). Restricciones de aspecto léxico impuestas por los complementos temporales en español. Verba, 41, 279-302. Santiago de Compostela: Universidade de Santiago de Compostela.

Miguel, E. de (1999). El aspecto léxico. En: I. Bosque \& V. Demonte (Dirs.). Gramática descriptiva de la lengua española (vol. 2) (pp. 2977-3060). Madrid: Espasa Calpe.

Moreno de Alba, J. G. (2003). ¿Puede ser imperfecto el pretérito perfecto? En: Estudios sobre los tiempos verbales (pp. 101-119). México: UNAM.

Moreno de Alba, J. G. (2006). Valores verbales de los tiempos pasados de indicativo y su evolución. En: C. Company Company (Dir. $\left.{ }^{a}\right)$. Sintaxis histórica de la lengua española. Primera parte: La frase verbal, vol. 1 (pp. 3-92). México: FCE y UNAM.

Nebrija, E. A. de (1492). Gramática de la lengua castellana. Recuperado de http://www. antoniodenebrija.org/indice.html

Ocampo, A. M. (2008). The Present Perfect in Spanish: A Study on Semantic Variation. California: University of South California.

Penny, R. (2008). Gramática histórica del español (3a reimpr.). Barcelona: Ariel.

Pérez Galdós, B. (1883/2003). El doctor Centeno. Alicante: Universidad de Alicante.

Pérez Galdós, B. (1884/2002). Tormento. Alicante: Universidad de Alicante.

Pérez-Rioja, J. A. (1952/1987). Gramática de la lengua española (7a ed.). Madrid: Tecnos. 
Porto Dapena, J. Á. (1989). Tiempos y formas no personales del verbo. Madrid: Arco Libros.

Roa Bastos, A. (1960/1977). Hijo de hombre. Madrid: Alfaguara.

Real Academia Española. (2010). Nueva gramática de la lengua española. Manual. Bogotá: Planeta.

Rojo, G. (1974). La temporalidad verbal en español. Verba, (1), 68-149. Santiago de Compostela: Universidade de Santiago de Compostela.

Rojo, G. (1990). Relaciones entre temporalidad y aspecto en español. En: I. Bosque (Ed.). Tiempo y aspecto en español (pp. 17-41). Madrid: Cátedra.

Rojo, G., \& Veiga, A. (1999). El tiempo verbal. Los tiempos simples. En: I. Bosque \& V. Demonte (Dirs.). Gramática descriptiva de la lengua española (vol. 2) (pp. 2867-2934). Madrid: Espasa Calpe.

Sábato, E. (1948/1986). El túnel. Madrid: Cátedra.

Schwenter, S. A., \& Torres Cacoullos, R. (2008). Defaults and indeterminacy in temporal grammaticalization: The 'perfect' road to perfective. En: Language Variation and Change, 20(1), 1-39. Cambridge: Cambridge University Press.

Spinoza, B. (2001). Ética demostrada según el orden geométrico (2a ed.). Madrid: Alianza.

Tobón de Castro, L., \& Rodríguez Rondón, J. (1974). Algunas consideraciones sobre el aspecto verbal en español. Thesaurus: Boletín del Instituto Caro y Cuervo, 39(1), 34-47. Bogotá: Instituto Caro y Cuervo.

Toledo y Huerta, Á. S. O. de., \& Rodríguez Molina, J. (2008). En busca del tiempo perdido: historia y uso de bube cantado. En: Á. Carrasco Gutiérrez (Ed. $)^{2}$. Tiempos compuestos y formas verbales complejas (pp. 275-358). Madrid y Frankfurt am Main: Iberoamericana-Vervuert.

Vásquez González, J. A. (2015). Sobre la teoría de la temporalidad lingüística de Guillermo Rojo. Estudios de Lingüística Aplicada (ELA), (62), 175-219. México: UNAM, Centro de Enseñanza de Lenguas Extranjeras.

Veiga, A. (1992). La no independencia funcional del aspecto en el sistema verbal español. Español Actual, (57), 65-80. Madrid: Arco Libros.

Veiga, A. (2004a). La forma verbal cantaba y la estructura modo-temporal del sistema verbal español. En: L. García Fernández \& B. Camus Bergareche (Eds.). El pretérito imperfecto (pp. 96-193). Madrid: Gredos.

Veiga, A. (2004b). Cantaba y canté. Sobre una hipótesis temporal y alguna de sus repercusiones. En: J.L. Cifuentes Honrubia \& C. Marimón Llorca (Coords.). Estudios de Lingüística: el 
verbo (ELUA), Anexo 2 (pp. 599-614). Alicante: Universidad de Alicante. Departamento de Filología Española, Lingüística General y Teoría de la Literatura.

Veiga, A. (2008). 'Co-pretérito' e 'irreal' / 'imperfecto' e 'inactual'. El doble valor de la forma cantaba en el sistema verbal español y algunos problemas conexos. Lugo: Axac.

Veiga, A. (2011). El "pretérito perfecto" español y la noción temporal de ante-presente. Romanica Cracoviensia, 11, 433-448. Cracovia: Universidad Jaguelónica de Cracovia.

Veiga, A. (2015). La gramática académica y los problemas del aspecto en la descripción del verbo español. Borealis: An International Journal of Hispanic Linguistics, 4(2), 119-150. Tromsø: University of Tromsø, Septentrio Academic Publishing.

Veiga, A., \& Mosteiro Louzao, M. (2006). El modo verbal en cláusulas condicionales, causales, consecutivas, concesivas, finales y adverbiales de lugar, tiempo y modo. Salamanca: Universidad de Salamanca.

Veyrat Rigat, M. (1993). Aspecto, perífrasis y auxiliación: un enfoque perceptivo. Valencia: Universitat de València.

Viejo Fernández, X. (1998). Las formas compuestas en el sistema verbal asturiano. 0viedo: Universidad de Oviedo, Departamento de Filología Española.

Westerholm, D. (2010). Funciones del pasado en los sistemas verbales del español y del ruso. Romanica Gothoburgensia, (66). Göteborg: Göteborgs Universitet. 